\title{
SAP AND MOBILE APPLICATIONS
}

\author{
William Gruver, Georgia Southern University, wg00691@georgiasouthern.edu \\ Camille Rogers, Georgia Southern University, cfrogers@georgiasouthern.edu
}

\begin{abstract}
This paper explores six articles of varying lengths that discuss mobile applications in general and in relation to SAP. We also relied on presentations given by SAP and Sybase professionals to interested users about the future direction of mobile technology in relation to their system. Babb (2010) suggests that the big-bang implementation of ERP software is out and there is money to make in other niches, including mobile technology. Kolakowski (2010) goes on to discuss SAP's acquisition of mobile application developer Sybase and how it might affect SAP's strategy going forward. Through a press release by Sybase (2010), strategy is outlined going forward for the rollout of mobile applications. This paper examines the articles mentioned, as well as other sources found through research, to present information on mobile applications and how they interact with SAP's business strategy currently and moving forward.
\end{abstract}

Keywords: Mobile Applications, SAP, ERP

\section{ENTERPRISE BASED MOBILE APPLICATIONS}

As of 2009, SAP is the largest enterprise software provider in the world. The company's most well-known products are SAP ERP and SAP Business Object's software. In order to maintain a competitive advantage in the marketplace, SAP is always searching for the next large development in ERP while maintaining their current software package offerings. In order to accomplish this, they are developing creative ways to market themselves as well as attract new customers. This paper will first discuss generalities about mobile applications including where the market has been and what direction it is heading in. Furthermore, we will discuss the use of strategic partners and acquisitions by SAP to expand their reach. The stages of mobile development will be discussed also. Finally, specific mobile applications in use by SAP and their benefits will be mentioned.

According to the Mobile Marketing Association (2008), mobile applications are a rapidly developing segment of the global mobile market. The days of using a cellular telephone only for such tasks as placing a call are quickly diminishing. Also known as downloadables, mobile applications are common on most phones, even inexpensive entry level models. These applications help to send e-mail messages, download various games, and even read blogs all on a handheld device. In an article in Information Week just recently Montalbano (2010), the White House has even joined the mobile application revolution by suggesting its top ten mobile apps that someone must have.

Depending on what type of business you encounter on a daily basis, information is very important, especially real time data. In gleaning information from an SAP presentation at TECHED 2010 given by Thorsten Stephan, the number and type of IT connected mobile devices is dramatically changing. The IDC forecast referred to in this presentation stated that there will be one billion smart phones and 1.2 billion mobile workers by the year 2013, according to projections. Furthermore, mobility is driving the user-friendly reputation of IT with almost half of large enterprises supporting personally owned versus company owned devices. With the rapid ramp up of mobilization, a company must adapt to the changing work environment or be left behind in the world of virtualization. Half of all the surveyed companies in a Gartner and Forrester Analyst call stated they are planning to deploy some type of mobile application related to the work of their organization within twelve months.

\section{SAP SPECIFIC MOBILE APPLICATION VENDORS}

The preceding information gives a brief overview of how the business market is adjusting and moving towards working in a mobile environment. With regards to SAP, they have been diligently working with Sybase, a mobile applications developer, in order to develop a mobile working option for companies who implement SAP. As of July 2010 according to Kanarcus (2010), Sybase was acquired by SAP and moved from strategic partner to part of the SAP corporate operation. Much like Business Objects, Sybase will operate as a separate business unit. The deal 
was valued at $\$ 5.8$ billion and SAP co-CEO Bill McDermott said, "SAP pledges that the company will one day offer a full suite of ERP applications and business intelligence tools that can run on any device, at any place, at any time." Jeffery Hammond was quoted in this article as saying the following, "I expect SAP to promptly take advantage of Sybase's mobile expertise. Mobile is one of the hottest areas for future growth." After the acquisition, SAP did not waste any time by putting products out on the market for use. SAP and Sybase have already released mobile Customer Relationship Management (CRM) and workflow apps on Sybase Unwired. Also in the works are other mobile applications to work with SAP's existing Business Suite Applications, analytic and in-memory infrastructure, and enterprise information management, all with varying degrees of complexity and specificity.

While Sybase is the in-house solution for mobility within its product lines, there are other providers which offer compatibility with certain SAP products and services. Before the Sybase acquisition, Vivido Labs Mowego had been working on and was rolling out "micro applications" which focused on doing one horizontal task well, such as expense-report filing and purchase approvals, also known as "instant value" applications. According to Kanaracus (2010), SAP’s former North American CEO, Greg Tomb, heads the company. According to Tomb, "The Software represents an improvement on other mobile ERP efforts. In the past, people have replicated a back-end transaction on a front-end device.” The company's goal is simplicity, targeting casual rather than heavy users of SAP. Another perk to this avenue of operation is cost. Sybase roll outs are mainly for complex data and broadly based. Vivido can customize as necessary and muck quicker because of its varied focus. Because of the simplification of these mobile applications, users are charged a general subscription rate per month based on specific applications. Even though Sybase is the preferred SAP mobile provider and the major focus of this paper, Vivido offers a unique alternative to businesses looking for personalized attention. Some other mobile application developers specific to SAP include Leapfactor, 3i, and Sky Technologies.

When companies and users alike think about moving their business enterprise into the virtual world many questions come to mind. These questions include such things as, how much will it cost? Will I be able to work on my mobile device similar to my PC? and finally, what are the maintenance and IT requirements? These questions are very valuable and work in conjunction with the decision to go mobile. According to statistics given in a presentation by Sybase employees Brian Whitmarsh and Matt Carrier, seventy-five percent of all United States workers will be mobile in some form or fashion by the year 2013. On a global scale, thirty-five percent of the workforce will be mobile by 2013. These statistics are very overwhelming given that it is changing the way companies are able to do business by becoming more time conscious and productive. For example, a production company may receive raw materials on a regular basis. These raw materials may have paper shipping documents that have to be entered into the system for processing into a company's inventory. With a mobile device, documents could be scanned into the system and processed quicker to start the proper flow of documentation throughout a particular company and production facility.

\section{STAGES OF MOBILE DEVELOPMENT}

When it comes to mobility, processing power did not come into existence overnight. Twenty years ago, mobile computing was not even a thought, much less affordable on a wide scale. Computing on a mainframe lead to a client/server approach. In the early to mid-1990's, the internet revolutionized computing with e-mail and other webpage's available for viewing. As far as today's technology is concerned, we are moving into an unwired enterprise style framework in which information can be accessed from any device, at any time, and from anywhere. On the spectrum of computing power, we are on a global scale today vs. a local scale twenty years ago. Also in relation to users, we are less computer centric and more human or user centric. In mobile development, there can be what is thought of as two distinct stages of development: Mobile 1.0 and Mobile 2.0. These two stages overlap somewhat as corporations and other organizations phase a future portion into the normal activities.

As mentioned in the previous paragraph, there are two stage of mobile development: Mobile 1.0 and Mobile 2.0 discussed in Whitmarsh and Carrier's presentation (2010). The purpose of Mobile 1.0 is to extend the enterprise. By extending the enterprise, real time e-mail can be read on mobile devices and field service workers (i.e. sales staff) can download information they may need on sales calls before they leave for a sales trip. With the use of such devices as a handheld blackberry, receiving e-mail wirelessly is not cost prohibitive as much of the work of 
maintaining storage is done outside of the company. With Mobile 2.0, the objective is to not just extend but also transform the enterprise involved. To accomplish this, a company has to change its workers and high-level employees approach to technology. With this stage, more info can be read not only through e-mail, but also directly off a company's internal back end operation. For example, a salesperson is in the field and does not have a pricing sheet with them; one could be accessed directly through SAP's CRM so that a quote could be given to and signed by the customer without having to wait for pricing information. Transforming an enterprise is very important in Mobile 2.0, as it will allow a company to go and remain mobile as well as on the cutting edge of technology.

\section{MOBILITY PLATFORM}

When a company does go mobile, specifically with SAP, production capabilities and efficiencies are increased across the board, even affecting raw materials suppliers and the end-user. Most mobile applications available at this moment are for internal use, but users of the system outside the company are slowly being phased in. Some more traditional companies are concerned about the cost-benefit analysis in going mobile thinking it will not revolutionize their business and change their revenue stream. A full mobile SAP rollout may not work for each company. However, some benefits can be realized by integrating applications into the normal course of business. For Example, a plant operations manager can manage work orders, check on plant assets via a scheduling application, and check on parts inventory all with a handheld mobile device. Furthermore, a field technician would be able to manage work orders, map out service calls, and even receive a customer's signature after the work has been performed. There is not a one-size fits all approach to SAP mobile opportunities, but there are options that make finding something an organization needs much easier.

In thinking about potential applications to have developed for a company or to put into use, there are many choices placed into three broad categories. These three broad categories are native applications, Container/Player specific and custom-built applications. This paper will not go into detail about the types of applications but merely introduce them. Native applications are the most prevalent in the marketplace, both in the consumer and business arena. These applications are downloaded directly to a mobile device and designed to run with or without web access. Because of the rapid proliferation and updating of devices, it is sometimes easier to choose native applications rather than customizing for each device. The second broad category is the container/player category. These are less frequent in practice because they are specialized and usually for one specific purpose. An example of an industry that uses this type of mission critical device would be a utility company. The final category is custom-built. This is somewhat a combination of both uses previously mentioned and is based on a company's needs and preferences. Although not standard practice, Sybase usually starts with a native application and customizes as necessary to the client company's needs and preferences in order to minimize additional costs.

Sybase, now an SAP company, is the main source for mobile integration within the product lines offered by SAP. Sybase's Unwired platform, which will be discussed in a later paragraph, works in unison with Sybase Afaria. As talked about in Thorsten Stephan's presentation (2010), the goal of the Sybase Afaria platform is to manage mobility with complete confidence while paying special attention to power, flexibility, and security. Afaria is highly customizable base on a client's preferences and allows for ease of distribution and updating of applications. Flexibility is also a main characteristic of Afaria. When it comes to flexibility, Afaria can be hosted or serviced onpremise can be used on a wide variety of devices, and services large and small-scale mobile deployments. With regards to security, Sybase and SAP are industry leaders in secure computing and will do everything in their power to make sure every rollout is secure and is working properly. One final advantage of Afaria is great technical support throughout the device lifecycle from programming to retirement. When a client notifies Sybase of the changing of devices or that a device has been compromised, everything in their power is done to ensure data is secure and not able to be accessed by outside parties. Afaria is a great device management tool but the main concern of most companies is how to go mobile.

The main focus of Sybase is to develop mobile applications which are supported by the use of Afaria and the Unwired Platform. The Unwired platform has many goals as mentioned in Carrier and Whitmarsh's presentation, including but not limited to, lowering the total cost of ownership of a mobile platform, integrating with existing platforms, ease of issue to market, and remaining current on mobile device trends and issues. Most companies are 
hesitant at first about accepting the mobile computing environment because of perceived cost. With Sybase Unwired, no development expertise is needed in-house which allows a client to simplify the process and let a third party worry about the details. With regards to integration, a company can choose which phases of business it wants to go mobile with, possibly starting slowly with the option to expand at a later time. Furthermore, once integration is taken care of, it is very easy to roll-out different mobile applications when very little customization is needed. Most IT professionals recommend little to no customization unless it is necessary because of the high costs involved. It is much better to customize on an as-needed basis. Finally, the end user of a device will not have to go searching for updates to his or her mobile applications; this will be done automatically through reminders, much like in a normal computing environment.

The discussion of the Unwired Platform and Afaria leads into the mobile applications that are currently available from Sybase in circulation to SAP mobile users worldwide. There are many applications available, the two main one's being Sybase Mobile Sales for SAP CRM and Sybase Mobile Workflow for SAP. The goal of Sybase and SAP is to have each module available for use in the normal Business Suite in mobile form sometime in the near future with no definite date set for development and rollout. According to a press release by Sybase (2010), Kevin Nix, senior vice president, Business Solutions and Technology, SAP AG said, "Over the last few years, we have seen significant shifts in the expectations of end users and their relationship with enterprise software. The new generation of business users demands immediate access to SAP solutions anytime, anywhere, using mobile devices.” SAP is really putting a significant investment into mobile infrastructure since large scale deployments of ERP are decreasing. The Mobile Sales for CRM application helps to automate sales processes, increase productivity, and enhance customer service by giving sales professionals access through a variety of smartphones. The Workflow application helps workers on the go complete business processes such as workflow items and alerts and time recording and travel requests. Both of these applications should help to enhance the productivity in a business environment as well as save time and money in the long run. Sybase is working very diligently to have these applications available for all smart phones, but they are in use on the iPhone, iPad, Blackberry, Windows Mobile, and Symbian devices.

SAP, in collaboration with its wholly owned company Business Objects, has been slowly rolling out SAP Business Objects Mobile. This is outside of SAP's normal Business Suite but will provide the capability to determine and look at certain statistics while outside the normal working environment. The same content that is worked with on a normal personal computer can be accessed through the mobile device. Such things as business intelligence reports, key market statistics, and sales forecasts are just a few of the examples of information that can be accessed. With this type of information available, sales and other field service workers can provide the right customer, product, and work-order information at the touch of a button which will help to shorten sales cycles and also improve customer satisfaction. SAP Business Objects Mobile, like most mobile SAP applications, is a two-way application that enables users to affect changes on the server with real-time data in response to changes that may have occurred while in the field. The Business Objects mobile application is the last major mobile device ready application that has large implications which will be discussed in this paper. However, there are a few more points to touch on in the following paragraphs including: Mission Critical applications, instant value applications, and other apps available from SAP.

There is a bit of segmentation in the mobile marketplace which directly and indirectly affects how SAP will continue to do business. With a wide variety of clients and industries served, some may be more specialized and need more customization than others. With this type of variety, it is important to know up front what a client needs and to anticipate what they may need in the future in order to make informed suggestions. With this being said, most users of mobile technology do not need specialized devices and the devices that they do need are readily available in the marketplace. The previously mentioned information touches on the differences between instant value and mission critical applications. Mission critical applications are usually used for one purpose and very specialized in nature, not easily transferrable to another operation. These are rare in practice but an example was mentioned in earlier discussion about utility companies using them to read meters. Where mission critical is concerned, the tasks are usually performed offline and business logic is contained on the device. However, instant value applications are more widespread, easily transferrable to a device, up and running very quickly, and business logic runs on a remote server. Obviously, mission critical devices, although useful, are not widely used in practice. 
On the other hand, instant value applications are easy to use, easily customizable, and both consumer and business friendly. Because of this reason, SAP, through the operation of Sybase, is in the business of creating predominantly instant value applications which are easier to work with. This does not preclude SAP from working on and with mission critical developments, but their focus is on widespread development of instant value applications.

Since we have talked at length about CRM, Business Objects, and Mobile Workflow, it is at least worth mentioning other applications that have been developed and are in use. The Workflow, CRM, and Business Objects applications are considered instant value apps, but they are larger in scope and size than some of the other ones that are smaller and more specialized in nature. Some of the smaller instant value applications in development and already in use include: Employee Lookup, Travel Expense Capture, ERP Sales Lookup, and Mobile Stream Work. SAP is not the only company involved in developing these types of apps. There are other vendors who support and service applications that work with and within the SAP ERP framework. Part of the outlook and part of SAP's mission for instant value is to develop these types of applications quickly, efficiently, and with a high return on investment for clients. Expanding on this philosophy, they want to be able to instantly develop, provide instant value, and an instant return on investment.

It is also important to mention the SAP Business by Design application that is currently available for the iPhone given that it caters to a different set of SAP clientele. The SAP Business by Design app is a mobile version of SAP's on-demand Enterprise Resource Planning (ERP) software. This application is designed for a client to be able to manage accounts, contacts, and activities, create sales orders and check product availability, send approvals and forward tasks to others while away from a PC, and view any personalized reports (i.e. sales, production, revenue projections). The Business by Design Mobile and in regular form are designed for small to mid-sized companies who may not possess the computing power necessary to have their own infrastructure in place to run SAP. In a press release by SAP AG printed on tradingmarkets.com (2010), Peter Lorenz, Executive Vice President for small and mid-size companies and a corporate office with the company says, "Customers today have to run real time businesses with a mobile workforce that needs to quickly make decisions no matter where they are located. This mobile app for SAP Business By Design is an integral step in delivering greater value for all users and expanding our on-demand business.” This is a first version of the app and many more versions planned to be rolled out making additional scenarios available and more devices compatible with further issues of the application.

\section{FUTURE OF MOBILITY}

Finally, it is very important to discuss the future of mobility. SAP and the mobile market are at a crossroads at this point. The mobile market adds a completely new dimension to computing, but it has an exciting future as well. Thirty years ago, computers were very large in relation to what they were able to do and were not very common, even in large companies. What used to be done with paper, pencil, and a filing cabinet is now performed with intricate processes and large databases. There is still future development to be made in mobile applications in the enterprise, consumer, and retailer and supplier area. On the consumer side, SAP and other companies are working on apps that would allow a customer to interact with a product, receive electronic coupons, and an easy to use "oneclick" consumer experience. In addition, on the retailer side, the goal is to be able to interact with the consumer in real time, design and run mobile marketing campaigns, and analyze consumer behavior in the field. The goal of this retailer/consumer interaction is to drive traffic to a particular area, influence consumer behavior in a positive way, and increase sales and overall revenues.

It has been very interesting learning about different mobile apps. It is also amazing to think personal computers were rare not twenty-five years ago and how far technology and mobility has come in such a short time span. With the acquisition of Sybase, SAP will continue to develop multiple mobile applications and strengthen their position as a leader in enterprise resource planning solutions. The future of mobile applications seems to be endless, but competitive at the same time. As long as there is a demand for mobile applications, companies will continue to design, perfect, and implement mobile strategies. SAP is on the cutting edge of business technology and will have to strive hard to maintain this competitive advantage. SAP and its associated technologies are not the company they once were when formed back in the 1970's, they are better positioned for continued growth. The future is bright for mobile applications, specifically in the corporate environment. 
Volume XII, No. 1, pp. 346-351, 2011

\section{REFERENCES}

1. Babb, P. (2010). “Is ERP as we know it dying”. InfoWorld. Retrieved from http://www.infoworld.com/print/114840

2. Carrier, M., Whitmarsh, B. Sybase Mobility [PowerPoint Slides] (2010). Retrieved From: http://www.sdn.sap.com/irj/scn/index?rid=/media/uuid/208d5484-59ac-2d10-c792-947ace577123

3. Kanarcus, C. (2010). “SAP Mostly Mum on Sybase Plans”. Computer World, Volume 44, Issue 10.

4. Kanarcus, C. (2010). "Startup rolls out a series of SAP mobile apps". InfoWorld. Retrieved from http://www.infoworld.com/print/117688

5. Kolakowski, N. (2010). "SAP Strategy involves iPad, Google Android”. eWeek. Retrieved from www.eweek.com

6. Mobile Marketing Association (2010). "More than one in three Consumers has downloaded mobile applications”. Retrieved from http://mmaglobal.com/news/more-one-three-us-consumers-have-downloadedmobile-apps

7. Montalbano, E. (2010). “White House Names Top Mobile Apps”. Information Week, government. Retrieved from http://www.informationweek.com/news/government/mobile/showArticle.jhtml?articleID=228400043

8. Stephan, T. SAP Mobile Strategy [PowerPoint Slides] (2010). Retrieved From: http://www.sdn.sap.com/irj/scn/index?rid=/media/uuid/208d5484-59ac-2d10-c792-947ace577123

9. Sybase Public Relations (2010). SAP and Sybase Deliver First Set of Applications to Millions of Mobile Workers Worldwide. Retrieved from: www.sybase.com 